\title{
Effect of the chemokine receptor CCR5 in the development of American cutaneous leishmaniasis in a Southern Brazilian population
}

\author{
ADRIANA DANMVOLF RIBAS ${ }^{1}$, REJANE CRISTINA RIBAS ${ }^{1}$, \\ WALDIR VERÍSSIMO DA SILVA JÚNIOR ${ }^{2}$, SANDRA MARA ALESSI ARISTIDES ${ }^{3}$, \\ MARIA VALDRINEZ CAMPANA LONARDONI ${ }^{3}$, MARIA ANGÉLICA EHARA WATANABE ${ }^{4}$, \\ SUELI DONIZETE BORELLI ${ }^{5}$ and THAÍS GOMES VERZIGNASSI SILVEIRA ${ }^{3}$
}

\author{
${ }^{1}$ Postgraduate Program in Health Sciences; ${ }^{2}$ Department of Biostatistics; ${ }^{3}$ Laboratory of Leishmaniasis, \\ Department of Clinical Analyses and Biomedicine, State University of Maringá, Maringá, Paraná 87020-900; ${ }^{4}$ Department of \\ Pathological Sciences, State University of Londrina, Londrina, Paraná 86051-990; \\ ${ }^{5}$ Laboratory of Immunogenetics, Department of Basic Health Sciences, \\ State University of Maringá, Maringá, Paraná 87020-900, Brazil
}

Received November 26, 2012; Accepted April 2, 2013

DOI: $10.3892 / \mathrm{mmr} .2013 .1452$

\begin{abstract}
American cutaneous leishmaniasis (ACL) shows a wide spectrum of clinical and immunopathological manifestations. The CCR5 chemokine receptor directs the immune response to a Th1 pattern and the mutant allele of this genotype $(\Delta 32 / \Delta 32)$ results in a less effective response, thus leading to a milder inflammation. The objective of the present study was to investigate the effect of the CCR5 chemokine receptor in the pathogenesis of ACL in a population of Southern Brazil. The frequency of the genotypes and their association with ACL were studied in 111 patients and compared with 218 control subjects. Genotyping was performed using samples amplified by polymerase chain reaction with sequence specific primers (PCR-SSP). The groups varied in chronological age $(\mathrm{P}<0.00001)$, but showed no differences in gender $(\mathrm{P}=0.0696)$ or ethnicity $(\mathrm{P}=0.2944)$. The frequency of the CCR5/ 322 genotype did not differ between the patient and control groups $(\mathrm{P}=0.3009)$. The $\Delta 32 /$ $\Delta 32$ deletion was not observed in any individual involved in the study. The analysis of the genotypes observed no significant difference in the frequency of the CCR $5 / \triangle 32$ genotype between the ACL and control groups, however the subgroup of patients with a recurrence of the lesion showed a higher frequency of the $C C R 5 / \triangle 32$ mutation $(P=0.020)$, indicating a possible effect of this allele in the pathogenesis of ACL.
\end{abstract}

Correspondence to: Professor Thaís Gomes Verzignassi Silveira, Av. Colombo 5.790, Bloco J-90, Sala 02, State University of Maringá, Maringá, Paraná 87020-900, Brazil

E-mail: tgvsilveira@gmail.com

Key words: American cutaneous leishmaniasis, CCR5, chemokines
Nevertheless, more studies are required to elucidate the role of CCR5 in the pathogenesis of ACL.

\section{Introduction}

Leishmaniasis is an infectious disease caused by protozoa of the genus Leishmania, transmitted by various species of sandflies. The parasite affects the skin, mucous membranes and viscera of vertebrate and invertebrate hosts as part of its life cycle $(1,2)$.

Leishmaniasis may present with varying clinical forms, depending on the Leishmania species involved and the relationship between the parasite and its host. Visceral leishmaniasis (VL) is a serious chronic disease whose fatality rate may reach $10 \%$ when no proper treatment is instituted (3). Cutaneous leishmaniasis (CL) is characterized by lesions which develop at the site of the bite of the vector (4).

According to the Pan American Health Organization (5), it is estimated that 2 million new cases of leishmaniasis occur each year worldwide, of which 1.5 million are cases of cutaneous leishmaniasis. It is estimated that $>12$ million individuals are infected with leismaniasis, which is considered one of the five most infectious and parasitic diseases of major relevance worldwide (6).

American cutaneous leishmaniasis (ACL) is a public health issue in Brazil and other countries of the New World. In the state of Paraná, where $>98 \%$ of the cases in Southern Brazil occur, ACL has been observed since the beginning of the twentieth century and notified since the 1980's. In the identification of the circuits of the disease, the North and West of Paraná were considered areas of epidemiological importance (7) and, according to the Ministry of Health, $>11,500$ new cases were reported between 1990 and 2010 (8). The cutaneous lesions of ACL are painless, singular or multiple areas, which develop in regions exposed to the bite of the vector, including the ears, face, upper and lower limbs. The mucosal lesions affect the 


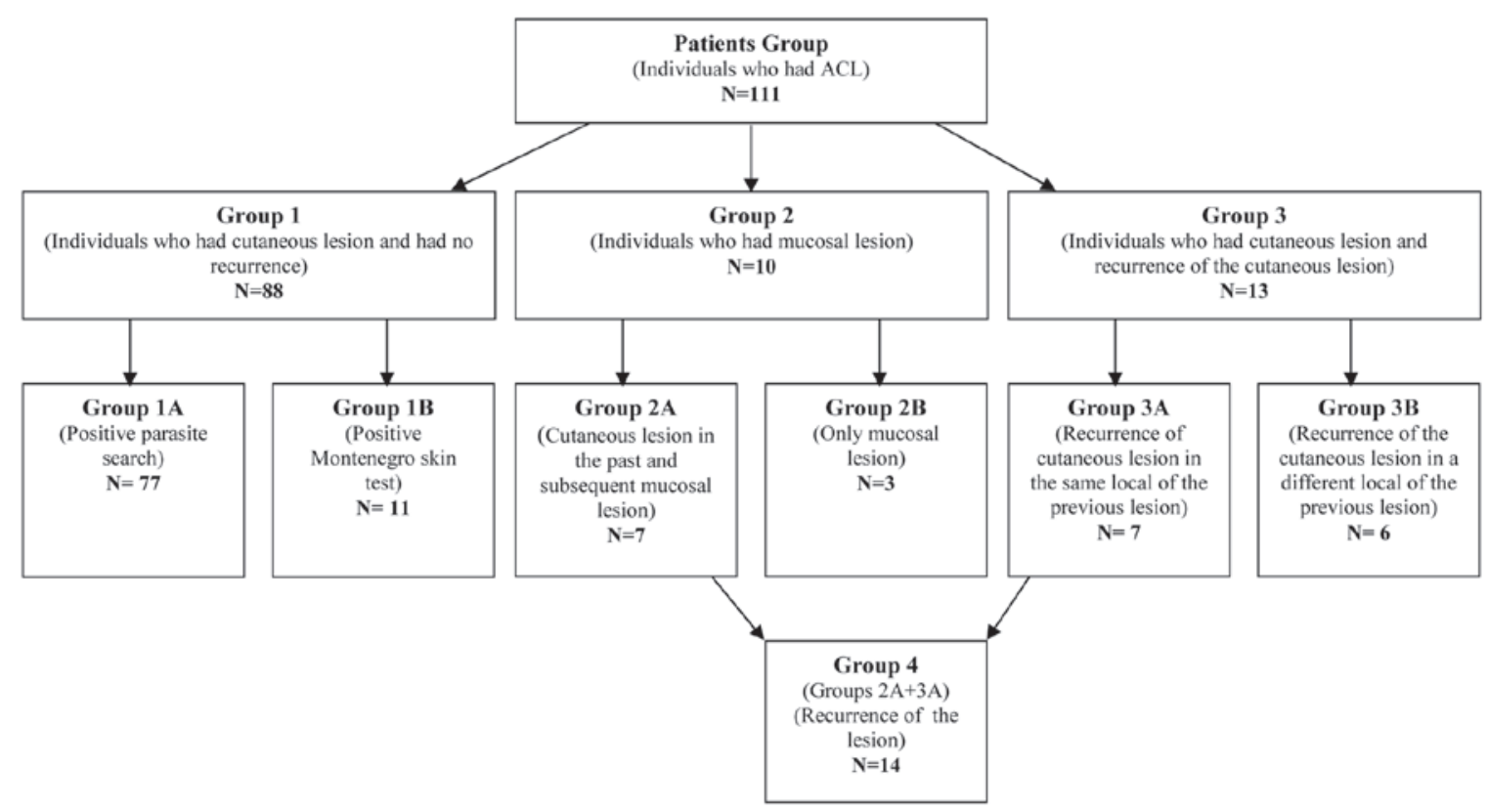

Figure 1. Composition of the patient groups and subgroups with American cutaneous leishmaniasis (ACL).

nose, mouth, throat and laryngeal cartilaginous tissue leading to destruction and disfigurement of the face (4).

Due to the wide spectrum of clinical and immunopathological manifestations, ACL has been examined in order to understand the mechanisms of host defense, which play a crucial role in the pathogenesis of the disease. It has been well-established that a protective immune response against Leishmania is dependent on the efficient development of a Th1 response, but on its own, the presentation of an antigen to a class II MHC is not sufficient to stimulate a T-cell response (9).

Chemokines play a significant role in the recruitment of host cells to the site of infection. The various chemokines act on different cells, thus controlling the nature of the inflammatory infiltrate. The chemokine CCL4, for example, acts on the CCR5 receptor, which plays a significant role in the recruitment of macrophages, monocytes and T cells (10-13). For this reason, chemokines are considered promising targets for the treatment of inflammatory, allergic, infectious and autoimmune diseases $(14,15)$.

CCR5 is a member of the family of transmembrane receptors coupled to the $\mathrm{G}$ protein (16). One mutation of this receptor gene consists of a deletion of 32 base pairs, designated as $\Delta 32$ (17), which results in a non-functional receptor, thus preventing its interaction with chemokine ligands $(18,19)$. Since the CCR5 molecule is typically expressed in cells that direct the immune response to Th1, which is associated with inflammation, the CCR5/ 32 non-functional allele results in a less effective Th1, consequently leading to a milder inflammatory state (20).

Findings of a previous study showed that the presence of the deletion allele is associated with a resistance to HIV infection and that it confers protection against asthma, rheumatoid arthritis, multiple sclerosis and renal graft rejection (21). Renal transplant recipients who are homozygous for a deletion have a significantly higher survival rate than recipients heterozygous or homozygous for the wild-type allele (22).
The CCR5 receptor is involved in directing the immune response towards a Th1, thus affecting the development of infectious diseases. As the various clinical forms of ACL depend on the host immune response, the CCR5 receptor may play a role in the development of the various forms of the disease. Thus, the aim of the present study was to investigate the effect of the CCR5 chemokine receptor in the development of ACL, in a population from the endemic areas in the north and northwest of the state of Paraná.

\section{Materials and methods}

Study design. A retrospective study was carried out on the epidemiological records of patients attending the Laboratory of Teaching and Research in Clinical Analysis of the State University of Maringá for laboratory diagnosis of ACL between 2000 and 2008. The diagnosis consisted of a search for parasites in the lesion and also a Montenegro skin test. An aliquot of $20 \mathrm{ml}$ peripheral blood was collected from all the patients and controls.

Control group. The control group comprised 218 healthy individuals. The inclusion criterion was being exposed to the same environmental risks as the ACL patients, i.e., those who had the habit of frequenting rivers in the endemic areas of the region but did not develop ACL. Blood relatives were excluded to reduce the likelihood of obtaining biased data.

Patients with ACL. The study included 111 patients who had been diagnosed positive for ACL and whose lesions did not return in the first 2 years subsequent to treatment. Blood relatives were not included in the study.

Composition of patient groups. The ACL patient group was divided into groups according to the clinical form of ACL, the results of laboratory tests and the clinical history (Fig. 1). 
Table I. Distribution of the control and patient groups according to age, gender and ethnicity.

\begin{tabular}{|c|c|c|c|c|c|c|c|c|c|}
\hline \multirow[b]{2}{*}{ Group } & \multirow[b]{2}{*}{$\begin{array}{l}\text { Average age } \\
\quad \text { (years) }\end{array}$} & \multicolumn{2}{|c|}{ Gender $^{b}$} & \multicolumn{6}{|c|}{ Ethnic group $^{c}$} \\
\hline & & $\begin{array}{c}\text { Female } \\
\mathrm{n}(\%)\end{array}$ & $\begin{array}{l}\text { Male } \\
\mathrm{n}(\%)\end{array}$ & $\begin{array}{l}\text { White } \\
\mathrm{n}(\%)\end{array}$ & $\begin{array}{c}\text { Mulatto } \\
\mathrm{n}(\%)\end{array}$ & $\begin{array}{c}\text { Oriental } \\
\mathrm{n}(\%)\end{array}$ & $\begin{array}{l}\text { Black } \\
\mathrm{n}(\%)\end{array}$ & $\begin{array}{l}\text { Indian } \\
\mathrm{n}(\%)\end{array}$ & $\begin{array}{c}\text { Total } \\
\text { (n) }\end{array}$ \\
\hline 'ontrol & 31.08 & $69(31.65)$ & 149 (68.35) & $171(78.44)$ & $32(14.75)$ & $6(2.75)$ & $8(3.67)$ & $1(0.46)$ & 218 \\
\hline Patient & 47.85 & $24(21.62)$ & $87(78.38)$ & $84(75.68)$ & $24(21.62)$ & $2(1.80)$ & $1(0.90)$ & $0(0.00)$ & 111 \\
\hline
\end{tabular}

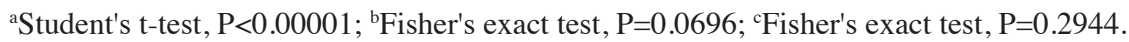

Group 1 comprised individuals who had presented with cutaneous lesions and showed no signs of a recurrence of the disease. This group was subdivided into group 1A consisting of 77 individuals who had received a positive parasitological diagnosis and group $1 \mathrm{~B}$ consisting of 11 individuals who only had a positive Montenegro skin test.

Group 2 included individuals who had mucosal lesions. This group was subdivided into group 2A composed of seven individuals with mucosal lesions who had previously had cutaneous lesions with a positive laboratory diagnosis (parasitological or the Montenegro skin test) and group 2B composed of three individuals who had mucosal lesions, without a previous history of cutaneous lesions.

Group 3 consisted of individuals who had cutaneous lesions which returned subsequent to treatment. This group was subdivided into group 3A, comprising seven individuals who had positive laboratory diagnoses (parasitological or the Montenegro skin test) and whose lesions had returned in the same location, as well as group $3 \mathrm{~B}$, comprising six individuals who had positive laboratory diagnoses (parasitological or the Montenegro skin test) and whose lesions had returned in a different location.

Group 4 consisted of all the individuals with a recurrence of the lesion (groups 2A and 3A). Recurrence was regarded as the appearance of a new lesion in the same location as the previous cutaneous lesion (group 3A) or in the mucosa (group 2A) subsequent to 2 years of treatment. This group comprised 14 individuals.

DNA extraction. The peripheral blood samples were placed in tubes containing EDTA anticoagulant at a concentration of $1.8 \mathrm{mg} / \mathrm{ml}$ and centrifuged at $960 \mathrm{~g}$ for $10 \mathrm{~min}$. The nucleated cells were separated (buffy-coat) and frozen at $-80^{\circ} \mathrm{C}$ until use. Genomic DNA was extracted from the frozen cells $(100 \mu \mathrm{l})$ using the PureLink ${ }^{\mathrm{TM}}$ Polymerase Chain Reaction (PCR) Purification kit (Invitrogen, Carlsbad, CA, USA) following the manufacturer's instructions.

Quantification of DNA. The genomic DNA was quantified using the Quant-iT ${ }^{\mathrm{TM}}$ dsDNA BR Assay kit in a Qubit ${ }^{\mathrm{TM}}$ fluorometer (Invitrogen, Eugene, OR, USA).

Optimization of PCR for CCR5. The method of genotyping was optimized in the Laboratory of Immunogenetics of the State University of Maringa using specific primers for CCR5 to amplify the genomic DNA. Primers CCR5.1 (sense primer,
5' CAA AAA ACC TCT GAA AGA 3') and CCR5.2 (antisense primer, 5' CAT GGT GAT GAA GAT AAG CCT CA 3') were designed according to the GenBank sequence AF009962 (23).

The sample from each individual was amplified by PCR with sequence specific primers (PCR-SSP). Amplification was carried out at $94^{\circ} \mathrm{C}$ for $5 \mathrm{~min}$, then 35 cycles at $94^{\circ} \mathrm{C}$ for $1 \mathrm{~min}$, $58^{\circ} \mathrm{C}$ for $1 \mathrm{~min}, 72^{\circ} \mathrm{C}$ for $1 \mathrm{~min}$ and $72^{\circ} \mathrm{C}$ for $10 \mathrm{~min}$ in a thermocycler GeneAmp ${ }^{\text {TM }}$ PCR System 9700 (Applied Biosystems, Foster City, CA, USA) and stored at $-18^{\circ} \mathrm{C}$ until the analysis.

All DNA amplification reactions were performed in parallel with negative controls to detect the possibility of contamination. The 225 and 193 base pair products were analyzed by electrophoresis on a $2.5 \%$ agarose gel, together with a standard molecular ladder of $50 \mathrm{bp}$ (Invitrogen) and visualized using UV fluorescence subsequent to being stained with SYBR ${ }^{\mathrm{TM}}$ Safe (Invitrogen).

Statistical analysis. To organize the CCR5/CCR5, CCR5/ 32 and $\Delta 32 / \Delta 32$ genotypes, a database was created in Excel 2007 and analysis was performed using the Statistical 7.0 program. The gender or ethnic group variables were analyzed by a Fisher's exact test and the age variable was analyzed by a Student's t-test for independent samples. The odds ratio (OR) was calculated with a confidence interval (CI) of $95 \%$ for $\mathrm{P}<0.05$. $\mathrm{P}<0.05$ was considered to indicate a statistically significant difference.

Ethical aspects. The present study was submitted to the Human Research Ethics Committee of the State University of Maringa and approved according to report No. 153/2009. All individuals were informed of the purpose of the study. Those who agreed to participate provided written informed consent, with full liberty to withdraw from participation at any time without any prejudice, as stated in resolution 196/96-CNS.

\section{Results}

The variables of age, gender and ethnicity were analyzed (Table I) in the patients with ACL (patient group) and the healthy subjects (control group). The chronological age of the patient group was statistically different from the control group $(\mathrm{P}<0.00001)$. The patients were 47 years old on average and the controls were 31 years old on average. With regard to gender, the two groups did not differ statistically $(\mathrm{P}=0.0696)$, but the majority of the subjects studied, $78 \%$ of the patients and $68 \%$ of the controls, were male. There was no statistical 
Table II. Distribution of genotypes CCR5/CCR5 and CCR5/A32 in the groups studied.

\begin{tabular}{lcrr}
\hline & \multicolumn{2}{c}{ Frequency } & \\
\cline { 2 - 3 } Genotypes & Patients & Control & P-value \\
\hline CCR5/CCR5 & 99 & 202 & \\
CCR5/A32 & 12 & 16 & 0.3009
\end{tabular}

Fisher's exact test. Confidence interval (CI), 0.697-0.359; Odds ratio (OR), 1.53.

Table III. Absolute distribution and percentage of the homozygous (CCR5/CCR5) and mutated (CCR5/ $\Delta 32)$ gentotypes in the patient groups and subgroups $(2 \mathrm{~B}, 4,3 \mathrm{~A}, 2$ and 3$) \mathrm{com}-$ pared with subgroup $1 \mathrm{~A}$.

\begin{tabular}{|c|c|c|c|c|}
\hline Group & $\begin{array}{c}\text { CCR5/CCR5 } \\
\mathrm{n}(\%)\end{array}$ & $\begin{array}{c}\mathrm{CCR} 5 / \Delta 32 \\
\mathrm{n}(\%)\end{array}$ & $\begin{array}{c}\text { Total } \\
\mathrm{n}\end{array}$ & P-value \\
\hline $1 \mathrm{~A}$ & $70(91)$ & $7(9)$ & 77 & \\
\hline $2 \mathrm{~B}$ & $2(67)$ & $1(33)$ & 3 & 0.2741 \\
\hline 4 & $14(100)$ & $0(0)$ & 14 & 0.5899 \\
\hline $3 \mathrm{~A}$ & $7(100)$ & $0(0)$ & 7 & 1.0000 \\
\hline 2 & $9(90)$ & $1(10)$ & 10 & 1.0000 \\
\hline 3 & $11(85)$ & $2(15)$ & 13 & 0.6127 \\
\hline
\end{tabular}

Group 1A, individuals who presented with cutaneous lesions and showed no signs of recurrence of the disease and had a positive parasitological diagnosis; group 2B, individuals who had mucosal lesions, without a previous history of cutaneous lesions; group 4, consisted of all the individuals with recurrence of the lesions (groups $2 \mathrm{~A}$ and $3 \mathrm{~A}$ ); group $3 \mathrm{~A}$, individuals who had a positive laboratory diagnosis and whose lesions returned in the same location; group 2 , individuals who had mucosal lesions; and group 3 , individuals who had cutaneous lesions which returned subsequent to treatment.

difference in ethnicity between the patient and control groups $(\mathrm{P}=0.2944)$. The populations examined showed no significant deviation from the Hardy-Weinberg equilibrium.

The CCR $5 / \Delta 32$ genotype was observed in $10.81 \%(12 / 111)$ of the subjects in the patient group, but in only $7.34 \%(16 / 218)$ of the control group. The $\Delta 32 / \Delta 32$ deletion was not observed in the studied population. The frequency of genotypes CCR5/CCR5 and CCR5/ 32 did not differ between the patient and control groups $(\mathrm{P}=0.3009$; Table II).

The comparison of the frequency of the genotypes between the ACL patients who showed no recurrence of the lesion subsequent to treatment (group 1A) and the other groups revealed no difference in the genotype distribution (Table III).

The analysis of the genotypes of the control group versus the patient groups and subgroups showed that only the group of individuals who had cutaneous lesions with a positive laboratory diagnosis and whose lesions returned in a different location (Group 3B) presented with a different distribution than the control group. This meant that the CCR5/A32 mutation was more frequent in this group $(\mathrm{P}=0.020$; Table IV).
Table IV. Absolute distribution and percentage of the homozygous (CCR5/CCR5) and mutated (CCR5/ 32 ) genotypes in the patient groups and subgroups compared with the control group.

\begin{tabular}{|c|c|c|c|c|}
\hline Group & $\begin{array}{c}\text { CCR5/CCR5 } \\
n\end{array}$ & $\begin{array}{c}\mathrm{CCR} 5 / \Delta 32 \\
\mathrm{n}\end{array}$ & $\begin{array}{c}\text { Total } \\
\mathrm{n}\end{array}$ & P-value \\
\hline Control & $202(92 \%)$ & $16(8 \%)$ & 218 & \\
\hline 1 & $79(89 \%)$ & $9(11 \%)$ & 88 & 0.4890 \\
\hline 2 & $9(90 \%)$ & $1(10 \%)$ & 10 & 0.5467 \\
\hline 3 & $11(84 \%)$ & $2(16 \%)$ & 13 & 0.2682 \\
\hline 4 & $14(100 \%)$ & $0(0 \%)$ & 14 & 0.6063 \\
\hline $1 \mathrm{~A}$ & $70(91 \%)$ & $7(9 \%)$ & 77 & 0.6249 \\
\hline $1 \mathrm{~B}$ & $9(64 \%)$ & $2(36 \%)$ & 11 & 0.2102 \\
\hline $2 \mathrm{~A}$ & $7(100 \%)$ & $0(0 \%)$ & 7 & 1.0000 \\
\hline $2 \mathrm{~B}$ & $2(67 \%)$ & $1(33 \%)$ & 3 & 0.2144 \\
\hline $3 \mathrm{~A}$ & $7(100 \%)$ & $0(0 \%)$ & 7 & 1.0000 \\
\hline \multirow[t]{3}{*}{$3 B$} & $4(67 \%)$ & $2(33 \%)$ & 6 & 0.0020 \\
\hline & $\mathrm{OR}=0.1584$ & $\mathrm{OR}=0.3125$ & & \\
\hline & $(0.03-0.93)$ & $(1.07-37.14)$ & & \\
\hline
\end{tabular}

Group 1, individuals who presented with cutaneous lesions and showed no signs of recurrence of the disease; group 1A, individuals who had a positive parasitological diagnosis; group $1 \mathrm{~B}$, individuals who only had a positive Montenegro skin test; group 2, individuals who had mucosal lesions; group 2A, individuals with mucosal lesions who had cutaneous lesions with a positive laboratory diagnosis; group 2B, individuals who had mucosal lesions, without a previous history of cutaneous lesions; group 3 , individuals who had cutaneous lesions that returned subsequent to treatment; group $3 \mathrm{~A}$, individuals who had a positive laboratory diagnosis and whose lesions returned in the same location; and group 3B, individuals who had a positive laboratory diagnosis and whose lesions returned in a different location. OR, odds ratio.

\section{Discussion}

In the last 20 years the incidence of ACL has increased in all the states of Brazil (3). This increase was primarily attributable to behavioral and environmental changes, including invasions in primary forests, deforestation, massive migration from rural to urban areas and rapid and unplanned urbanization (3). Therefore, due to the increase in the number of cases and the wide spectrum of clinical and immunopathological manifestations of ACL, the aim of the present study was to evaluate the potential effect of the chemokine receptor CCR5 in the varying forms of ACL.

In the present study, the patients were older than the controls. The ACL patients were 47 years old on average while the controls were 31 years old on average. The age range of the patients was as expected as the ACL occurs more frequently in older patients (24).

It was observed that the majority of the patients were male. These results were expected as males more commonly conduct leisure activities, including hunting and fishing, that involve the risk of contracting ACL (24). Thus, the control group comprised a higher proportion of males to the remaining paired data.

CCR 5 studies have demonstrated the importance of the $\Delta 32$ mutation, particularly in the susceptibility to HIV infection, 
since CCR5 is a co-receptor in the primary stage of infection that is essential for the onset of the disease (25). Therefore, it was expected that the populations most affected by the virus would have a higher degree of gene deletion, however, mutations of this gene may have occurred in fatal generalized epidemics that occurred in Europe and not due to the HIV virus. Prior to HIV, the bubonic plague would have affected the mutation. A recent study has demonstrated that smallpox may also have affected the mutation since the smallpox virus uses the CCR5 and CXCR4 as receptors to enter cells (26). Other studies have suggested that the CCR $5 / \Delta 32$ mutation may prevent the development of cerebral malaria, slow multiple sclerosis (27) and prolong graft survival in kidney and heart transplants (28), but controversy remains with regard to liver transplants (29).

In the present study, which analyzed a population of the north and northwest of the Paraná state, a frequency of $\sim 10 \%$ was identified for the CCR5/ $\triangle 32$ genotype, corroborating the results of other investigators who had studied the frequency of this genotype in the northern population of the state $(30,31)$. A frequency of $7 \%$ was observed in an urban population of CCR5/A32 individuals (32). Another study based on four tribes in the Brazilian Amazon observed that the population was $100 \%$ homozygous for the normal allele, which supports the hypothesis that the $\Delta 32$ allele has a European origin and that its occurrence in the populations of South America is a result of immigration (33). The highest frequency of the $\Delta 32$ allele (20.93\%) was recorded in Jewish populations (with Israeli ancestry) and in Eastern Europe, which are both known to be highly inbred (34). Among African-Americans this frequency is $<1 \%$ and among Caucasians in Asia (Pakistan and India), there is also a very low frequency of this mutation. This allele has not been reported in China, Japan or native African populations (34).

There were no individuals with the homozygous recessive genotype in the present study. The frequency of the $\Delta 32 / \Delta 32$ genotype is $\sim 1 \%$ in the population of Eastern Europe (17). Thus, the chance of identifying a homozygous deleted individual is extremely small and consistent with the genotypes observed in this population.

There was no difference in the frequency of the CCR5/CCR5 and CCR5/ $\triangle 32$ genotypes between the patient control groups in the present study, showing that these alleles had no effect on the development of ACL. These results corroborated the results of another study which also identified no differences in the frequency of these alleles among its study groups (30).

The analysis of the frequency of the alleles in the patient subgroups when compared with the control group showed an association between the CCR5/ $\triangle 32$ genotype and group $3 \mathrm{~B}$ (individuals who had a positive laboratory diagnosis and whose lesions returned in a different location). The recurrence of cutaneous lesions may be due to an immune deficiency of the host or infection by parasitic subspecies capable of inducing immunosuppression in the host (35). The present study data suggested that the CCR $5 / \Delta 32$ genotype may be associated with the reappearance of the cutaneous lesions in ACL, although the number of patients in this group was small.

There was also no difference in the allele frequency between the subgroup of the individuals who presented with cutaneous lesions and had a positive parasitological diagnosis with no signs of recurrence of the disease within a period of at least 2 years (group 1A) and the other patient subgroups. This showed that there was no correlation between the alleles and the various groups of ACL patients that were studied.

In the present study, the $\Delta 32$ allele was also observed in the patients of groups $2 \mathrm{~B}$ (individuals who had mucosal lesions, without a previous history of cutaneous lesions) and 3B (individuals who had a positive laboratory diagnosis and whose lesions returned in a different location). This result was in contrast with a study that observed that the heterozygous patients only had cutaneous lesions (30). According to this study, the Th1 immune response was associated with the non-functional allele CCR5/ $\triangle 32$ genotype, leading to a milder immune response.

The present study showed no difference in the frequency of the CCR5/ $\triangle 32$ genotype between the patient and control groups, but there was a higher frequency of this genotype in the subgroup of patients who had a recurrence of cutaneous lesions in different locations to the primary lesion. However, due to the small number of patients in each subgroup, more studies are required to elucidate the role of CCR 5 in the pathogenesis of ACL, enabling advances in therapeutic treatments and new prophylactic strategies for the disease.

\section{Acknowledgements}

This study was supported by grants from the Araucaria Foundation and the Laboratory of Immunogenetics, Department of Basic Health Sciences, State University of Maringá, Brazil.

\section{References}

1. Rey L: Leishmania and leishmaníases: parasites. In: Parasitology, Editora Guanabara Koogan.3rd edition. Rio de Janeiro, p214-226, 2001.

2. Condino MLF, Galati EAB, Holeman MM, Salum MRB, Silva DC and Junior RAN: American cutaneous leishmaniasis on the northern coastline of São Paulo, 1993 to 2005. Rev Soc Bras Trop Med 41: 635-641, 2008 (In Portuguese).

3. Gontijo CMF and Melo MN: Visceral leishmaniasis in Brazil: current status, challenges and prospects. Rev Bras Epidemiol 7: 338-349, 2004 (In Portuguese).

4. Gontijo B and de Carvalho Mde L: American cutaneous leishmaniasis. Rev Soc Bras Med Trop 36: 71-80, 2003 (In Portuguese).

5. Pan American Health Organization: Leishmaniasis: 2007 update. http://www.paho.org/English/AD/DPC/CD/leish-2007. pdf. Accessed Feb 09, 2012.

6. Guerra JAO, Barbosa MGV, Loureiro ACSP, Coelho CP, Rosa GG, Coelho LIACR: American cutaneous leishmaniasis in children: epidemiological aspects of cases treated in Manaus, Amazonas, Brazil. Rep Public Health 23: 2215-2223, 2007 (In Portuguese)

7. Lima AP, Minelli L, Teodoro U and Comunello E: Distribution of cutaneous leishmaniasis by orbital remote sensing images, in Paraná State, Brazil. An Bras Dermatol 77: 681-692, 2002.

8. Brasil: Ministério da Saúde: Vigilância Epidemiológica 2012. http://portal.saude.gov.br/portal/saude/profissional/area.cfm?id_ area $=1560$. Accessed Feb 09, 2012.

9. Alexander J and Bryson K: T helper (h)1/Th2 and Leishmania: paradox rather than paradigm. Immunol Letters 99: 17-23, 2005.

10. Abbas AK: Cytokines. In: Cellular and Molecular Immunology. Abbas AK, Lichtman AH, Pillai S (eds). 6th edition. Elsevier, Rio de Janeiro, pp267-302, 2008.

11. Murphy PM: The molecular biology of leukocyte chemoattractant receptors. Annu Rev Immunol 12: 593-633, 1994. 
12. Baggiolini M: Chemokines and leukocyte traffic. Nature 392: 565-568, 1998 .

13. Proost P, Wuyts A and van Damme J: The role of chemokines in inflammation. Int J Clin Lab Res 26: 211-223, 1996.

14. Pereira AB, Rezende NA, Teixeira Jr AL, et al: Cytokines and chemokines in renal transplantation. J Bras Nefrol 31: 286-296, 2009 (In Portuguese).

15. Spagnolo P, Renzoni EA, Wells AU, et al: C-C chemokine receptor 5 gene variants in relation to lung disease in sarcoidosis. Am J Respir Crit Care Med 172: 721-728, 2005.

16. Guignard F, Combadiere C, Tiffany HL and Murphy PM: Gene organization and promoter function for CC chemokine receptor 5 (CCR5). J Immunol 160: 985-992, 1998.

17. Liu R, Paxton WA, Choe S, et al: Homozygous defect in HIV-1 coreceptor accounts for resistence of some multiply-exposed individuals to HIV-1 infection. Cell 86: 367-377, 1996.

18. Yang X, Ahmad T, Gogus F, et al: Analysis of the CC chemokine receptor 5 (CCR5) Delta32 polymorphism in Behçet's disease. Eur J Immunogenet 31: 11-14, 2004.

19. Sidoti A, D'Angelo R, Rinaldi C, et al: Distribution of the mutated delta32 allele of the CCR5 gene in a Sicilian population. Int J Immunogenet 32: 193-198, 2005.

20. Chies JA and Hutz MH: High frequency of the CCR5delta32 variant among individuals from an admixed Brazilian population with sickle cell anemia. Braz J Med Biol Res 36: 71-75, 2003

21. Zúñiga JA, Villarreal-Garza C, Flores E et al: Biological relevance of the polymorphism in the CCR5 gene in refractory and non-refractory rheumatoid arthritis in Mexicans. Clin Exp Rheumatol 21: 351-354, 2003.

22. Fildes JE, Walker AH, Howlett R, et al: Donor CCR5 Delta32 polymorphism and outcome following cardiac transplantation. Transplant Proc 37: 2247-2249, 2005.

23. GenBank. http://www.ncbi.nlm.nih.gov/nuccore/AF009962. Accessed Apr 05, 2010.

24. Silveira TG, Arraes SM, Bertolini DA, Teodoro U, et al: The laboratory diagnosis of epidemiology of cutaneous leishmaniasis in Paraná State, southern Brazil. Rev Soc Bras Med Trop 32: 413-423, 1999 (In Portuguese).
25. Galvani AP and Novembre J: The evolutionary history of the CCR5-Delta32 HIV-resistance mutation. Microbes Infect 7: 302-309, 2005.

26. Stanford Medicine Schoool.http://www.thetech.org/genetics/news. php?id=13. Accessed Feb 12, 2012.

27. Lamb A: CCR5-delta32: a very beneficial mutation. J Creation 20: 15,2006

28. Pereira AB, Rao NA, Teixeira AL Jr, Teixeira MM, Silva ACS Cytokines and chemokines in renal transplantation. J Bras Nefrol 31: 286-296, 2009 (In Portuguese).

29. Li H, Xie HY, Zhou L and Zheng SS: Lack of association of the polymorphism of the CCR5 gene in liver recipients with acute rejection from China. Exp Clin Transplant 9: 252-257, 2011.

30. Oliveira KB, Reiche EMV, Morimoto HK et al: Analysis of the $\mathrm{CC}$ chemokine receptor 5 delta32 polymorphism in a Brazilian population with cutaneous leishmaniasis. J Cutan Pathol 34: 27-32, 2007.

31. Muxel SM, Borelli SD, Amarante MK, et al: Association study of CCR5 delta 32 polymorphism among the HLA-DRB1 Caucasian population in Northern Paraná, Brazil. J Clin Lab Anal 22: 229-233, 2008

32. Passos GA Jr and Picanço VP: Frequency of the delta CCR5 deletion allele in the urban Brazilian population. Immunol Lett 61: 205-207, 1998

33. Leboute AP, de Carvalho MW and Simões AL: Absence of the deltaCCR5 mutation in indigenous populations of the Brazilian Amazon. Hum Genet 105: 442-443, 1999.

34. Martinson JJ, Chapman NH, Rees DC, Liu YT and Clegg JB: Global distribution of the CCR5 gene 32-basepair deletion. Nature Genet 16: 100-103, 1997.

35. Brasil. Ministério da Saúde. Manual de vigilância da leishmaniose tegumentar Americana. Brasília, DF, p181, 2007. 